\title{
Optimization of MBR hydrodynamics for cake layer fouling control through CFD simulation and RSM design
}

\author{
Min Yang ${ }^{\mathrm{a}, \mathrm{b}}$, Dawei Yu ${ }^{\mathrm{a}, \mathrm{b}}$, Mengmeng Liu ${ }^{\mathrm{a}, \mathrm{b}}$, Libing Zheng ${ }^{\mathrm{a}, \mathrm{b}}$, Xiang Zheng ${ }^{\mathrm{c}}$, Yuansong Wei ${ }^{\mathrm{a}, \mathrm{b}, *}$, \\ Fang Wang ${ }^{\mathrm{d}}$, Yaobo Fan ${ }^{\mathrm{a}, \mathrm{b}, *}$

 \\ ${ }^{\mathrm{b}}$ College of Resources and Environment, University of Chinese Academy of Sciences, Beijing 100049, China \\ ${ }^{c}$ School of Environment and Nature Resources, Renmin University of China, Beijing 100872, China \\ ${ }^{\mathrm{d}}$ School of Energy and Power Engineering, Beijing University of Aeronautics and Astronautics, Beijing 100191, China
}

\section{H I G H L I G H T S}

- CFD model and RSM design was developed for mitigation of cake layer fouling in MBR.

- Sludge concentration was the most decisive for shear stress and particle deposition.

- MLSS of $8820 \mathrm{mg} \mathrm{L}^{-1}$ was optimal for the reduction of reversible membrane fouling.

- Bubble diameter was more decisive than air flowrate for membrane shear stress.

\section{A R T I C L E I N F O}

\section{Article history:}

Received 4 November 2016

Received in revised form 4 December 2016

Accepted 6 December 2016

Available online 9 December 2016

\section{Keywords:}

CFD

MBR

Hydrodynamics

Fouling

Cake layer

\section{G R A P H I C A L A B S T R A C T}

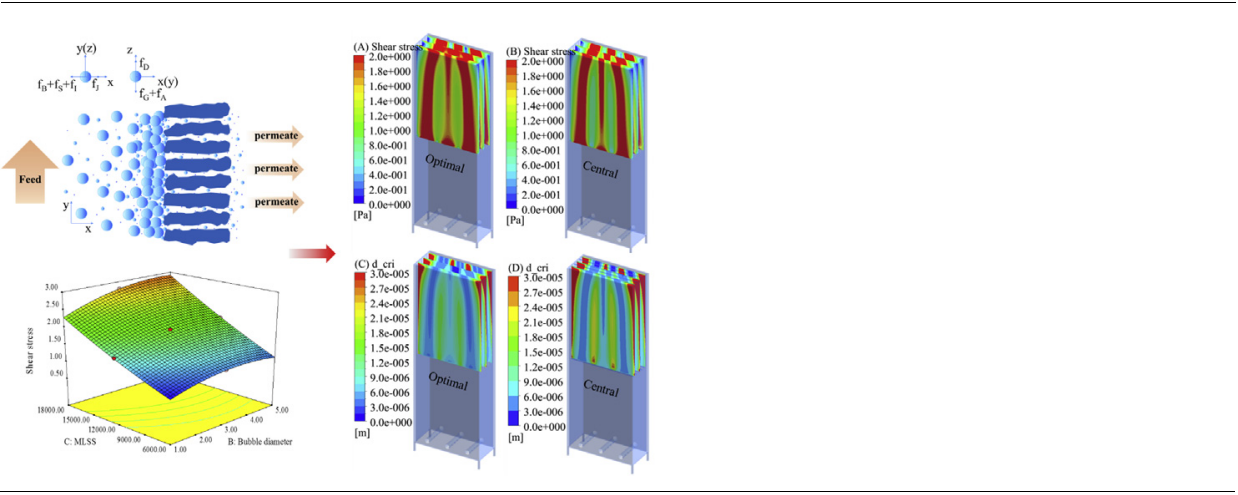

A B S T R A C T

Membrane fouling is an important issue for membrane bioreactor (MBR) operation. This paper aims at the investigation and the controlling of reversible membrane fouling due to cake layer formation and foulants deposition by optimizing MBR hydrodynamics through the combination of computational fluid dynamics (CFD) and design of experiment (DOE). The model was validated by comparing simulations with measurements of liquid velocity and dissolved oxygen (DO) concentration in a lab-scale submerged MBR. The results demonstrated that the sludge concentration is the most influencing for responses including shear stress, particle deposition propensity (PDP), sludge viscosity and strain rate. A medium sludge concentration of $8820 \mathrm{mg} \mathrm{L}^{-1}$ is optimal for the reduction of reversible fouling in this submerged MBR. The bubble diameter is more decisive than air flowrate for membrane shear stress due to its role in sludge viscosity. The optimal bubble diameter was at around $4.8 \mathrm{~mm}$ for both of shear stress and PDP.

(c) 2016 Elsevier Ltd. All rights reserved.

\footnotetext{
* Corresponding authors at: College of Resources and Environment, University of Chinese Academy of Sciences, Beijing 100049, China.

E-mail address: ybfan@rcees.ac.cn (Y. Fan).
}

\section{Introduction}

Membrane bioreactor (MBR) is an attractive process in space limited areas by replacing the secondary sediment tank for the purpose of separation of water and biomass in wastewater treatment due to its small footprint (Judd, 2011). However, membrane fouling, as the most challenging issue in MBR application, needs 
physical and (or) chemical cleaning when it comes to a critical point (Chen et al., 2016; Wang et al., 2014). Nevertheless, it is possible to control fouling before its occurrence. Membrane foulants can be divided into three fractions considering particle diameter as bio-solids, colloids, and dissolved solutes (Wang et al., 2014). The solutes and colloids adsorb to membrane surface and pores, and this fouling is regarded as irreversible and generally removed by chemical cleaning. The bio-solids (microbial aggregates, flocs) deposit on the membranes and often accumulate to compact 'cake layer' which is considered as the main cause of fouling problems (Wang et al., 2014). The main factors for MBR membrane fouling control can be separated into four categories as widely reported (Lin et al., 2014; Shen et al., 2015; Yu et al., 2014) as following: activated sludge conditions (including MLSS, particle diameter, viscosity, rheology, SMP, EPS, F/M, surface tensions, zeta potential), operations (bubble diameter, aeration, HRT, SRT, flux, addition of powdered activated carbon or flocculants), configuration (membrane module, reactor) and membrane materials (hydrophobicity, hydrophilicity, membrane structure). Obviously, hydrodynamics has a strong interaction with each one of the above four aspects. The measures to limit sludge cake fouling include the operation under sub-critical flux, the improvement of hydrodynamic conditions, the implementation of intermittent filtration, the addition of flocculants, the selection of proper sludge retention time (SRT), and hydraulic retention time (HRT) (Wang and Wu, 2009). It is well known that hydrodynamics plays the key role in the reversible fouling control such as detachment of cake layer and bio-solids migration (Wang and Wu, 2009). It is clear now that one cure for membrane fouling can be the systematical analysis of effect of hydrodynamics on reversible fouling. In general, shear force is the main consideration for the deprivation of cake layer. As a result, most numerical studies pursued high shear stress through operations such as the increase of aeration intensity and the change of bubble diameter (Böhm et al., 2013). However, the diffusion generated force is more decisive than shear force for the back transportation of bio-solids and cake layer (Drews et al., 2010; Judd, 2011). The parameters influencing particle diffusion and the corresponding optimization were not critically considered. The particle size, for instance, which has limited contribution to the shear stress but is decisive for the bio-solids deposition through diffusion, is often ignored (Amini et al., 2013). This can be a reason why the controversial findings about the particle size related operations on membrane filtration were found (Rosenberger et al., 2005). Meng (Meng et al., 2006) suggested that particle size distribution (PSD) should be taken as a separate membrane fouling factor due to its small correlation with EPS in most MBR operations though some researches showed that particle size may be impacted by the amounts and components of EPS (Wilén et al., 2003). The biomass concentration in the bulk and in the cake layer should also be reconsidered due to its role in both of shear stress and particle diffusion. MLSS concentration can be negative or positive or no impact on membrane fouling as reported (Rosenberger et al., 2005). Schwarz (Schwarz et al., 2006) summarized that increasing MLSS decreased the critical permeate flux, but the effect was strong only for MLSS $<\sim 5 \mathrm{~g} \mathrm{~L}^{-1}$. For the typical MLSS zone $\left(>\sim 5 \mathrm{~g} \mathrm{~L}^{-1}\right)$, flux-management techniques to prevent serious cake formation were more important than MLSS. Same situations were found for bubble size. The increase of bubble size can be negative (Drews et al., 2010) or positive (Böhm et al., 2013) on membrane filtration resistance. While some others reported that there was a plateau region of shear stress with the increase of bubble diameter (Amini et al., 2013). To resolve such paradox for MBR operations, the operations related to hydrodynamics for membrane fouling control should be re-examined by introducing more factors affecting hydrodynamics and the physical effects of these parameters need to be separated from biological ones (EPS, SMP).
Hydrodynamics evaluation then can be a supplement for the analysis of biological fouling caused by solutes and collides. Jiang (Jiang et al., 2007) set an example to make the controversies explicit. In his study, the submicron particle deposition in a side-stream membrane bioreactor was controlled to some extent through the modification of five variables related to hydrodynamics, i.e., cross flow velocity, membrane tube diameter, membrane length, dry solid contents and temperature while considering the PSD and sludge viscosity. Amini (Amini et al., 2013) introduced a CFD model to study the effect of operations including MLSS concentration and bubble diameter on the membrane shear stress of a full-scale MBR. They found that higher MLSS was preferred for membrane scouring and the optimized bubble diameter was $3 \mathrm{~mm}$ within the restrained range of $2 \mathrm{~mm}-5 \mathrm{~mm}$ irrespective of the MLSS concentration. However, the sludge was treated as Newtonian fluid in these studies and the interrelated relationship of different operations was ignored, which left the conclusions of these studies in dispute. Besides, the key control parameter such as dissolved oxygen (DO) was not considered and thus makes these researches far from practical guidance. The hydrodynamics of particle deposition is very complex involving mass and momentum balances, multiphase interaction and species transportation (ANSYS, 2014). More specifically, particle back transporting, membrane scouring and DO concentration can be affected by temperature, airflow rate and mode, bubble shape and diameter, biomass concentration and PSD. This study therefore highlights the comprehensive evaluation and optimization of hydrodynamics on reversible fouling considering sludge conditions (PSD, MLSS and sludge rheology), operations (bubble diameter and aeration intensity) and DO concentration in a lab-scale flat sheet MBR through CFD simulation. It has to be pointed out that it is the thermodynamic forces (interactions between membrane and flocs) that bind (adhere) flocs to the membrane after the flocs move close to the membrane surface by hydrodynamic forces (Lin et al., 2014). Such thermodynamic forces can be described by the extended Derjaguin-LaudauVerwey-Overbeek (XDLVO) theory which presumes that the total interaction is the sum of attractive Lifshitz-Van der Waals, repulsive electrostatic double layer and acid-base interaction. These three thermodynamic interactions between membrane surface and foulants are functions of their separation distance and surface properties. The XDLVO forces can be affected by many factors such as solution $\mathrm{pH}$, solution ionic strength, surface properties, fractal dimension and floc size etc, and play decisive roles in the final adhesion of sludge foulants (Hong et al., 2014; Lin et al., 2014). However, they are not considered in this study due to its distraction from the focus of this study and the impossibility to acquire the sufficient Nano-level resolution with a CFD modeling of a macro-scale. The traditional one-by-one experiment optimization is time consuming and implicit, and brings misleading results by neglecting the interactions between the input parameters. An expedite methodology is of great needs to evaluate the responses including particle back transporting and membrane scouring in a straightforward manner. The design of experiments approach allows understanding the main interactions between the input parameters and successfully targeting the best operating conditions of MBR with a minimum number of runs.

The objectives of this paper are thus (1) to investigate the mechanism and effect of MLSS, bubble diameter, aeration on reversible fouling such as cake layer on the membrane of MBR with the CFD simulation and DOE design, and (2) to obtain the cost-effective control of membrane reversible fouling targeting different responses from the hydrodynamic and practical prospective. Responses of wall shear stress and probability of particle deposition (PDP) under a restrained DO concentration are studied, and the optimal operations of the MBR in favor of one of or both of the two responses are determined. 


\section{Material and methods}

\subsection{Experimental setup}

A bench-scale submerged flat sheet MBR with a work volume of $60.0 \mathrm{~L}$ was used (Fig. 1). Five flat membrane sheets $\left(0.07 \mathrm{~m}^{2}\right.$ per sheet, effective filtration area $0.05 \mathrm{~m}^{2}$ for each membrane side) (SINAP membrane tech Co., Ltd., China) with a design flux of $20.0 \mathrm{~L} \mathrm{~m}^{-2} \mathrm{~h}^{-1}$ were packed in the membrane module settled in the geometrical middle of the reactor. The two sides of each membrane sheet were named in forms of ' $\mathrm{m}_{i, a}$ ' and ' $\mathrm{m}_{i, b}$ ', where ' $i$ ' was the membrane series number along y direction, and ' $a$ ' and ' $b$ ' indicated the front and back of each membrane sheet, respectively. Three aeration blowers were perpendicular to the membrane surfaces. To generate different bubble size, different groups of blowers with different air-blower orifices' diameter were prepared.

Hexahedral mesh was generated by using ICEM 15.0 (ANSYS, USA). Local meshes near wall and air-blower orifices were refined and mesh size increased with a growth rate of 1.2 to improve the numerical stability. More layers of meshes were inflated near membrane surface to improve the numerical resolution of these areas. After the grid independent test, the optimized grid used in this work was around 720,000 elements with the maximum and minimum element sizes of $10.0 \mathrm{~mm}$ and $0.5 \mathrm{~mm}$, respectively. All the simulations were carried out in FLUENT ${ }^{\circledR} 15.0$ (ANSYS, USA) on a work station (Thinkstation D30, LENOVO, China) with a 64 bit processor (Intel ${ }^{\circledR}$ Core $^{\mathrm{TM}} 12$ Xeon CPU E5649) and 24 GB of random access memory, running at a clock speed of $2.53 \mathrm{GHz}$.

\subsection{Design of experiments of the membrane filtration process}

The requirement of a large number of experiments can be very time consuming. Besides, traditional one-by-one experimental optimization is implicit and leads to misleading results by neglecting the interactions between the input parameters. To make the conclusion explicit, the CFD simulations were carried out with the design of experiments approach. The central composite (CCD) approach was applied as the response surface methodology (Silva and Rouboa, 2015). CCD approach allows the understanding the main interactions between the input parameters and successfully targeting the best operating conditions with a minimum number of CFD simulations. The operating conditions of MLSS, airflow rate and bubble diameter in the MBR were chosen due to the remarkable effect on membrane fouling control (Tijing et al., 2015; Wibisono et al., 2014). The ranges of the operations were determined according to the practical MBR operation (Table 1).

\subsection{Sampling and analysis}

Rheology of activated sludge samples from the MBR was measured by a Haake RS6000 Rheometer ${ }^{\circledR}$ (Thermo Scientific, USA). The measurements were performed in triplicate at shear rates ranging from 0 to $500 \mathrm{~s}^{-1}$. The measuring protocol in detail is referenced to previous work (Yang et al., 2016). The non-Newtonian relationships between shear stress and shear rate were fitted to the yield-pseudo plastic type Sisko rheology model using Matlab ${ }^{\circledR}$ (Mathworks, Inc.). Different biomass concentrations were acquired by diluting or concentrating the sludge adopted from the lab-scale MBR rather than by adjusting the F/M or SRT. PSD of sludge was measured by Malvern particle size analyzer (Mastersizer 2000, England). Activated sludge samples were taken from a steadily operated MBR with a SRT of $20 \mathrm{~d}$ for SOUR measuring. The oxygen concentration of the sludge samples was automatically recorded by the fluorescence DO meter (Multi 3410, WTW Co Ltd, Germany) every 10 seconds. The overall volumetric respiration rate (OUR) was calculated from the decreasing concentration of oxygen in the respirometric cell between aeration phases. After that, the sludge was taken out for the measurements of MLSS (mixed liquor suspended solid) and MLVSS (mixed liquor volatile suspended solid) concentrations.

DO concentrations at points of $\mathrm{S} 1$ (25 mm, $175 \mathrm{~mm}, 25 \mathrm{~mm}), \mathrm{S} 2$ (175 mm, $100 \mathrm{~mm}, 750 \mathrm{~mm}), \mathrm{S} 3(325 \mathrm{~mm}, 25 \mathrm{~mm}, 500 \mathrm{~mm})$ were measured with a fluorescence DO meter (Multi 3410, WTW Co Ltd, German) (Fig. 1). The average value of these three DO concentrations was obtained and compared to that of the CFD modeling.

PIV (EM3-03M1500, Microvec Pte. Co., LTD, China) was adopted for the water velocity measurement. Pure water velocity measurements were firstly carried out in the MBR at an airflow rate of $1.0 \mathrm{~m}^{3} / \mathrm{h}$. Carboxymethyl cellulose (CMC) and xanthan were then used to replace activated sludge as a rheological fluid for velocity

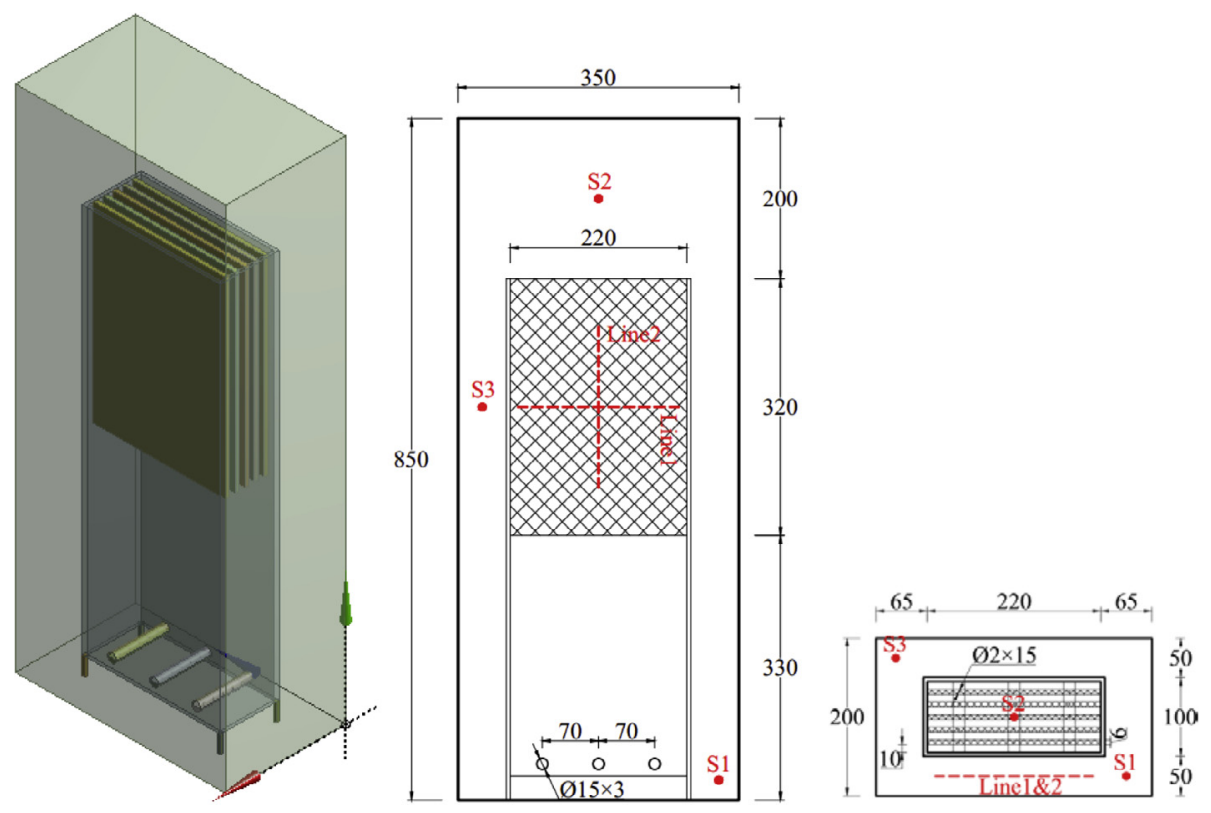

Fig. 1. Airlift membrane bioreactor in 3D view and its configuration parameters in orthographic views. 
Table 1

Operating conditions and corresponding ranges used for the design of experiments.

\begin{tabular}{ll}
\hline Operating conditions & Operating range \\
\hline MLSS $\left(\mathrm{g} \mathrm{L}^{-1}\right)$ & $6.0-18.0$ \\
Air flow rate $\left(\mathrm{m}^{3} \mathrm{~h}^{-1}\right)$ & $1.0-2.0$ \\
Bubble diameter $(\mathrm{mm})$ & $1.0-5.0$ \\
\hline
\end{tabular}

measurements with PIV system due to their transparency and pseudo plastic fluids behavior which is similar to the activated sludge (Böhm and Kraume, 2015; Ratkovich et al., 2010). A concentration of $0.5 \% w / w$ was used to represent the sludge concentration of around $12.0 \mathrm{~g} \mathrm{~L}^{-1}$ (Dumont et al., 2002). Water velocities outside the membrane module $\left(\mathrm{L}_{1}\right.$ and $\left.\mathrm{L}_{2}\right)$ were recorded (Fig. 1). Testing procedures of PIV can be found in the previous work (Yang et al., 2016).

\section{Model development}

\subsection{Governing equations of gas-liquid flow}

The three-dimensional two-phase mass and momentum conservation equations are solved by the pressure-based solver where the pressure field is shared by the different phases. Each phase is governed by respective mass and momentum conservation equations within the multiphase framework of Euler-Euler (ANSYS, 2014). The drag force is considered to be the contribution to interphase momentum transfer described by Schiller-Naumann model (ANSYS, 2014). The RNG $k-\varepsilon$ model is applied for turbulence closure (ANSYS, 2014).

\subsection{Sludge rheology and membrane shear stress}

The sludge rheology is a key parameter concerning membrane fouling not only because it has significant impact on flow pattern, but the important role it plays in sludge viscosity and the shear rate (Ratkovich et al., 2013). The viscosity of activated sludge was known to differ with many factors, among of which the biomass concentration (MLSS) was known to be the decisive factor (Moreau et al., 2009). In this study, the impacts of other sludge characteristics, such as EPS, SMP, hydrophobicity-hydrophilicity, bio-polymeric clusters (BPC) which have little impacts on sludge viscosity, were excluded by using the same sludge suspension for each test. The sludge rheograms for MLSS from $3 \mathrm{~g} \mathrm{~L}^{-1}$ to $18 \mathrm{~g} \mathrm{~L}^{-1}$ were measured at $\mathrm{T}=20^{\circ} \mathrm{C}$ (Fig. S1) and then fitted as a function of shear rate and MLSS concentration using Sisko model in MATLAB $^{\circledR}$ (Mathworks, Inc., USA), which brought to the following expression.

$$
\begin{aligned}
\eta & =6.35 \mathrm{e}^{-4}+2.73 \mathrm{e}^{-3} \operatorname{MLSS}^{1.65} \gamma^{-0.54}(\text { Pa s }), 3 \mathrm{~g} \mathrm{~L}^{-1} \leqslant \text { MLSS } \\
& \leqslant 18 \mathrm{~g} \mathrm{~L}^{-1}, \mathrm{R}^{2}=0.9958
\end{aligned}
$$

where $\eta$ (Pa s) is apparent laminar viscosity, MLSS $\left(\mathrm{g} \mathrm{L}^{-1}\right)$ is biomass concentration, $\gamma\left(\mathrm{s}^{-1}\right)$ is strain rate.

It has to be pointed out that the different biomass concentrations are acquired by diluting or concentrating the sludge adopted from the lab-scale MBR rather than by adjusting the F/M or SRT which may have important impact on sludge viscosity by changing of Microthrix parvicella abundance (Meng et al., 2007; Wagner et al., 2015) or biopolymers composition (Meng et al., 2006; Moreau et al., 2009). The apparent viscosity of pure water is $1.003 \mathrm{mPa}$ s and that of $\mathrm{CMC}$ at $25^{\circ} \mathrm{C}$ was represented as Eq. (2) according to (Dumont et al., 2002)

$\eta=0.16 \gamma^{-0.27}(\mathrm{~Pa} \cdot \mathrm{s}), \mathrm{R}^{2}=1.0000, \mathrm{c}=0.5 \% \mathrm{w} / \mathrm{w}, \mathrm{T}=25^{\circ} \mathrm{C}$
The membrane shear stress $\tau_{i j}(\mathrm{~Pa})$ is then calculated by,

$\tau_{i j}=\eta\left(\frac{\partial u_{i}}{\partial x_{j}}+\frac{\partial u_{j}}{\partial x_{i}}\right)$

\subsection{Particle back transport velocity}

The particles tend to transport to membrane surface due to the drag force of permeate flow which, however, can be offset mainly by the so called back transport forces including Brownian diffusion, $f_{\mathrm{B}}$ (influencing small colloids), shear-induced diffusion, $f_{\mathrm{S}}$ and inertial lift, (influencing big particles) (Belfort et al., 1994; Jiang et al., 2007) (Fig. 2).

For submicron particles, Brownian $\emptyset_{b}$ diffusion is important and is the integration of the one-dimensional convective-diffusion equation across the polarization boundary for dilute solutions $\left(\emptyset_{b} \ll \emptyset_{w}\right)$ (Belfort et al., 1994)

$J_{B}=K\left(\frac{\emptyset_{w}}{\emptyset_{b}}\right)^{1 / 3}$

where $K$ is a mass-transfer coefficient estimated by Eq. (5), $\emptyset_{b}$ and $\emptyset_{w}$ are the particle volume fractions at the edge of the cake layer and in the bulk suspension, respectively.

$K=1.31\left(\frac{\gamma_{w} D_{B}^{2}}{L}\right)^{1 / 3}$

where $\gamma_{w}$ is shear rate $\left(\mathrm{s}^{-1}\right), D_{B}\left(\mathrm{~m}^{2} / \mathrm{s}\right)$ is Brownian diffusion coefficient estimated by Eq. (6), $L$ is the tube or channel length (m).

$D_{B}=\frac{k T}{6 \pi \eta_{f} a}$

where $k$ is the Boltzmann constant $\left(1.38 \times 10^{-23} \mathrm{~kg} \mathrm{~m}^{2} / \mathrm{s}^{2}\right), T$ is the absolute temperature $(\mathrm{K})$ and $a$ is the particle radius $(\mathrm{m})$.

The Brownian diffusion model underestimates the particle back transport especially for large particles and at high shear rate conditions (Belfort et al., 1994). The shear-induced hydrodynamic diffusivity, which occurs because individual particles undergo random displacements from the streamlines in a shear flow as they interact with and tumble over other particles, was a possible resolution to the flux paradox (Davis and Sherwood, 1990). The back transport velocity due to shear-induced diffusion $\left(J_{S}\right)$ for a dilute solution $\left(\phi_{b}<0.1\right)$ proposed by (Davis and Sherwood, 1990) is as follows

$J_{S}=0.078 \gamma_{w}\left(\frac{a^{4}}{L} \frac{\phi_{w}}{\phi_{b}}\right)^{1 / 3}$

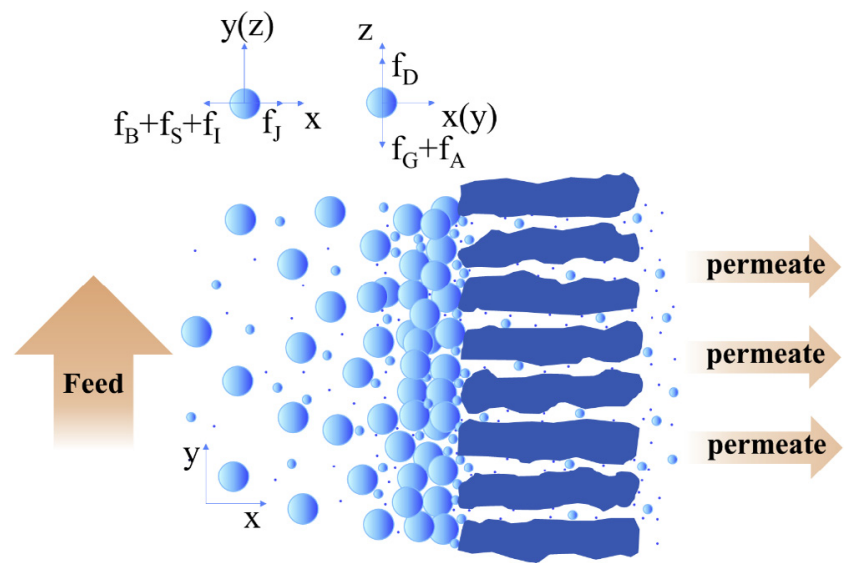

Fig. 2. Forces exerted on particles in an airlift flow membrane filtration process 
The shear-induced hydrodynamic diffusivity is proportional to the power of $2 / 3$ of the particle size multiplied by the shear rate (Eq. (7)), whereas the Brownian diffusivity is independent of shear rate and inversely proportional to particle size (Eq. (4)). As a result, Brownian diffusion is important for submicron particles and low shear rates, whereas it is dominated by shear-induced hydrodynamic diffusion in cross flow filtration involving micron-sized and larger particles.

The shear-induced diffusion proposed by Davis and Sherwood is still underestimated the diffusion in the concentrationpolarization boundary layer because the concentrationdependent viscosity employed in their model (Davis and Sherwood, 1990). To compensate this, an inertial lift mechanism was proposed by Belfort and co-workers (Belfort et al., 1994; Drew et al., 1991). Inertial lift arises from nonlinear interactions of a particle with the surrounding flow field under conditions where the Reynolds number based on the particle size is not negligible. It involves a lateral migration of particles, which transports particles away from the membrane. The back transport velocity due to inertial lift $\left(J_{I}\right)$ of spherical particles under laminar flow conditions in dilute suspensions, where particle-particle interactions are negligible, can be estimated as follows (Belfort et al., 1994)

$J_{I}=0.036 \frac{\rho_{f} a^{3} \gamma_{w}^{2}}{\eta_{f}}$

Particle-particle and particle-membrane interactions (including entropy, van der Waals interactions and electrostatic interactions), which may play roles in particle transportation to/from the membrane surface for concentrated solutions of colloidal particles but are insignificant for dilute solutions, are not considered in this study (Bowen and Sharif, 1998; Davis, 1992; Elimelech et al., 2013).

For the lab scale MBR in this study, an average back-transport flux at a typical operation, e.g. MLSS concentration of $8000.0 \mathrm{mg} \mathrm{L}^{-1}$, apparent viscosity of $6.0 \mathrm{mPa} \mathrm{s}$ at a strain rate around $150 \mathrm{~s}^{-1}$ (calculated by CFD) is calculated by Eq. (4) to Eq. (8). The back transport velocity cannot balance the suction force for particles with a diameter from $0.001 \mu \mathrm{m}$ to 1.0 (Fig. 3). It is reported that their reduction can hardly be improved by hydrodynamic approaches (Belfort et al., 1994). While for particles with a diameter larger than $100.0 \mu \mathrm{m}$, either shear deuced velocity or inertial velocity can overcome the suction force (Jiang et al., 2007). Particles with the diameter between $1.0 \mu \mathrm{m}$ to 100.0 are

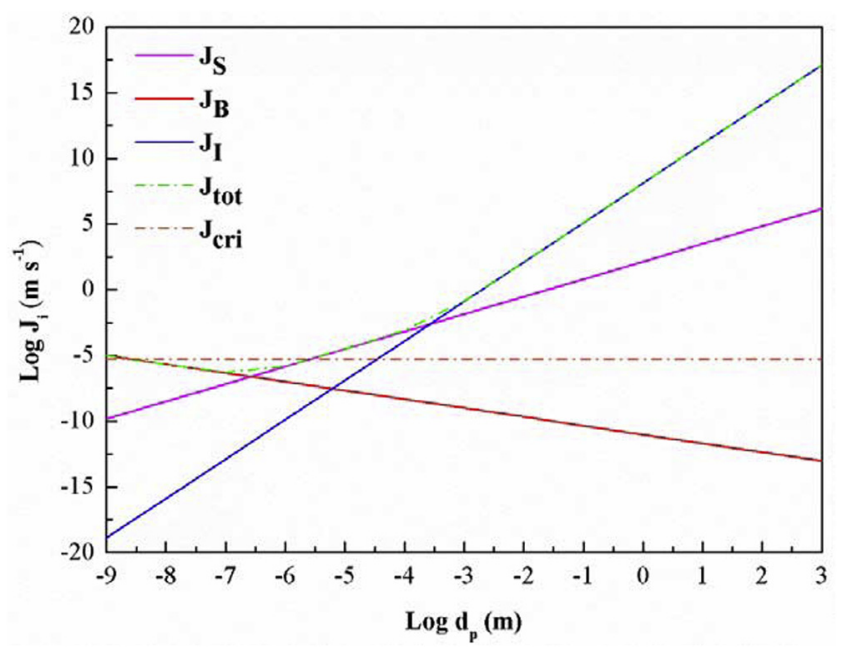

Fig. 3. Steady-state calculation of average back-transport flux against particle diameter for a crossflow filtration with thin cake layers in a typical lab-scale MBR run $\left(\mathrm{J}_{\mathrm{cri}}=20.0 \mathrm{~L} \mathrm{~m}^{-2} \mathrm{~h}^{-1}, \phi_{w}=60.0 \%, \phi_{b}=0.8 \%, \mathrm{~T}=293.15 \mathrm{~K}, \eta_{f}=0.006 \mathrm{~Pa} \mathrm{~s}\right.$, $\gamma_{w}=150.0 \mathrm{~s}^{-1}$, and $\left.\mathrm{L}=0.032 \mathrm{~m}\right)$. more sensitive to hydrodynamics and their transportations are dominantly controlled by shear induced force (Fig. 3).

\subsection{Oxygen biotransformation}

The DO concentration is expected to vary with the MBR operations. To coordinate the DO concentration and membrane scouring at a cost-effective way, the DO concentration is regarded as a restrictive factor in CFD simulation. The oxygen biotransformation considering biomass concentration, aeration intensity and bubble diameter is thus incorporated into the CFD model. The evolvement of DO in bioreactor is a result of balancing of oxygen transfer from gas to bulking liquid and oxygen consumption by microbial community. They are determined as follows.

\section{(1) Oxygen mass transfer} 2014)

The oxygen transfer rate (OTR) is estimated by (Pittoors et al.,

$\mathrm{OTR}=k_{L} \mathrm{a}\left(\alpha \mathrm{S}_{\mathrm{O}}^{*}-\mathrm{S}_{\mathrm{O}}\right)$

where $k_{L}$ a $\left(\mathrm{s}^{-1}\right)$ is the mass transfer coefficient estimated by Eq. (10), $\alpha$ is the oxygen saturation concentration ratio of wastewater to clean water (Tchobanoglous et al., 2002), $S_{\mathrm{O}}^{*}\left(\mathrm{mg} \mathrm{L}^{-1}\right)$ and $S_{0}$ $\left(\mathrm{mg} \mathrm{L}^{-1}\right)$ are the dissolved oxygen saturation concentration of clean water and dissolved oxygen in the liquid phase.

The $k_{L}$ a takes the form of (Cockx et al., 2001),

$k_{\mathrm{L}} \mathrm{a}=\beta \frac{12 \alpha_{\mathrm{b}}}{\mathrm{d}_{\mathrm{b}}} \sqrt{\frac{\mathrm{D}_{\mathrm{L}} \Delta \mathrm{U}}{\pi d_{\mathrm{b}}}}$

where $\beta$ is the coefficient considering the effect of wastewater property and sludge concentration, $\alpha_{b}$ is the gas volume fraction, $\mathrm{d}_{\mathrm{b}}(\mathrm{m})$ is the Sauter mean diameter of the bubbles, $\mathrm{D}_{\mathrm{L}}\left(\mathrm{m}^{2} \mathrm{~s}^{-1}\right)$ is diffusivity of oxygen in the liquid phase, and $\Delta U(\mathrm{~m} / \mathrm{s})$ is the slip velocity between bubbles and bulking liquid.

(2) Dissolved oxygen consumption

The oxygen uptake rate (OUR) is simplified as

OUR $=$ SOUR $_{\text {Cons }} \times$ MLVSS

where SOUR Cons $\left(\mathrm{h}^{-1}\right)$ is the specific oxygen uptake rate in the MBR tank, MLVSS ( $\mathrm{mg} \mathrm{L}^{-1}$ ) is the mixed liquor volatile suspended solid.

\section{Results and discussion}

\subsection{Model validation}

The model simulation was compared to experimental data measured in a lab-scale MBR. For hydrodynamics validation, liquid velocities in pure water and CMC solution $(0.5 \% \mathrm{w} / \mathrm{w})$ were measured, respectively. For species validation, DO concentration was measured in the MBR under 6 conditions of the 15 cases (Table 2).

Liquid velocity at $L_{1}$ and $L_{2}$ was obtained by the PIV measurement and by the CFD simulation, respectively. Good agreements of liquid velocities between the CFD simulations and the PIV measurements were achieved (Fig. S2). The average DO concentrations of 6 different runs were quite close to the CFD modeling, respectively (Fig. S3). All relative errors were less than 5\% suggesting that the model provided an excellent description of flow behavior and DO concentration distribution.

\subsection{Particle size distribution and sludge viscosity}

The particle size of MBR sludge varies with operations such as SRT (Hocaoglu et al., 2011), HRT (Meng et al., 2007), practical shear 
Table 2

Operating conditions for experimental runs for DO measurements.

\begin{tabular}{|c|c|c|c|c|c|c|}
\hline Experimental conditions & Run 1 & Run 2 & Run 3 & Run 4 & Run 5 & Run 6 \\
\hline Airflow rate $\left(\mathrm{m}^{3} \mathrm{~h}^{-1}\right)$ & 1.5 & 1.0 & 1.5 & 1.0 & 1.5 & 2.0 \\
\hline Bubble diameter (mm) & 3.0 & 3.0 & 3.0 & 5.0 & 5.0 & 5.0 \\
\hline $\operatorname{MLSS}\left(\mathrm{mg} \mathrm{L}^{-1}\right)$ & $12,000.0$ & $12,000.0$ & 6000.0 & 6000.0 & $12,000.0$ & 6000.0 \\
\hline Sludge organic loading rate $\left(\mathrm{kg} \mathrm{kg}^{-1} \mathrm{~d}^{-1}\right)$ & 0.076 & 0.076 & 0.153 & 0.153 & 0.153 & 0.076 \\
\hline
\end{tabular}

stress intensity (Stricot et al., 2010), flocculants addition (Liu et al., 2015) and influent characteristics (Hao et al., 2016). The particle size distribution of the MBR in this study showed a main peak at around $112 \mu \mathrm{m}$ and a long tail between 1 and $10 \mu \mathrm{m}$ (Fig. S4) which is consistent to the publications which had similar work conditions to this study (Massé et al., 2006; Stricot et al., 2010). The rate at which particles are carried to the membrane surface due to the permeate flow can be balanced by back-transport forces for particles with diameter larger than $100 \mu \mathrm{m}$ (Fig. 3). The smaller sludge $(1-10 \mu \mathrm{m})$ are more inclined to deposit due to the weak back transport velocity induced by all the three diffusions. These fine particles along with the soluble foulants (EPS/SMP) will quickly form a thin film and lead to a dramatic drop of permeate flux for the newly installed membranes or membranes after chemical cleaning. Given a critical flux, the critical size of particle deposition, $\alpha$ can be determined by Eq. (4) to Eq. (8). Then the total volume of particles deposited on membrane or the particles deposition propensity (PDP) can be calculated by,

$\mathrm{PDP}=w_{\alpha} \phi_{b}=\sum_{i=0}^{\alpha} V_{i} \phi_{b}$

where $w_{\alpha}(\%)$ is the percentage of deposited particles, $V_{i}$ is the particle volume fraction, $\phi_{b}\left(\mathrm{mg} \mathrm{L}^{-1}\right)$ is the biomass concentration of the bulk.

The impact of sludge viscosity on membrane scouring is two sides. The shear stress may get down at high sludge viscosity retarding the flow thus making lower shear rate on membrane, but on the other hand the shear stress may go up if the increase of sludge viscosity offsets the decrease of shear rate according to Eq. (3). Operating conditions such as aeration intensity and temperature and configuration of the MBR will impact sludge viscosity even at the same sludge concentration, which can partly explain the discrepancy of the impact of MLSS concentration on membrane filtration (Rosenberger et al., 2002; Stricot et al., 2010). At the same time, the sludge viscosity has an effect on strain rate and thus affects the particle deposition (Eq. (8) and Eq. (9)). As the most decisive factor for sludge viscosity, MLSS concentration is without doubt one of the major considerations for membrane scouring and particle back transportation.

\subsection{Single response optimization}

Fifteen CFD simulations were carried out by varying input factors of air-flow rate, biomass concentration and bubble diameter in agreement with the design of experiments approach. All the other parameters such as temperature, MBR configuration were kept the same. For each one of the fifteen simulations, a set of responses including shear stress, PDP, strain rate and DO concentration was set. The information of all the responses was extracted and was compiled to be used with a Response Surface Method. Data was fitted by using a second order empirical model implied by Response Surface Method and given by Eq. (13).

$\mathrm{y}=c_{0}+\sum_{i=1}^{3} c_{i} x_{i}+\sum_{i=1}^{3} c_{i, i} x_{i}^{2}+\sum_{i=2}^{3} \sum_{i>j}^{3} c_{i, j} x_{i} x_{j}$ where $y$ is the response, the $x_{i}$ terms are the input factors, the $c_{i}$ terms are coefficients. The use of this empirical model allows the determination of the optimal $x_{i}$ terms to optimize each one of the studied responses.

The empirical model was validated by using different statistical methods embedded in Design-Expert ${ }^{\circledR}$ software (Stat-Ease, Inc., USA) and can be used to navigate within the input parameters boundaries. The most important diagnostic methodology to inspect the effectiveness of the predicted model is the normal probability plot of the internal studentized residuals. It measures the number of standard deviations separating the actual and predicted values. The internal studentized residual, $r_{i}$, is the residual divided by the estimated standard deviation of that residual.

$r_{i}=\frac{e_{i}}{\sigma \sqrt{1-h_{i i}}}$

where $e_{i}$ is the difference between actual and predicted values for each point; $h_{i i}$ is the $i$ th diagonal entry in the hat matrix of the orthogonal projection onto the column space of the design matrix; $\sigma$ is population standard deviation.

All the models for each one of the responses behave as expected for a normal plot of residuals (Fig. S5). Further analysis was carried out by proceeding to the analysis of variance (ANOVA). The suggested empirical model was used to determine the best operating conditions. The use of replicates was not considered because it made no difference for the same scenario based on CFD simulation. As a consequence, some statistics such as the test on lack of fit and the pure error (Anderson and Whitcomb, 2005) was missing. Despite of these, ANOVA analysis for the model was carried out and the standard statistics for the model are given here (Table 3 ).

The $p$-values less than 0.05 indicate model terms are significant and the large $F$-values further ensure that the selected empirical models are significant. The $R$-Squared value, which measures how well the empirical model fits the CFD numerical simulation, however, increases by adding new terms. To compensate for this drawback, new statistics such as Adjusted $R$-Squared and Predicted $R$-Squared are also presented. The values of Predicted $R$-Squared for all responses are high and are in reasonable agreement with that of the Adjusted $R$-Squared (Table 3 ). The adequate precision measures the signal to noise ratio and a ratio greater than 4 is desirable (Silva and Rouboa, 2015). The ratios higher than 4 for all responses ensures that the model prediction of the responses can be used in the design space. In conclusion, all the statistical measures confirm that the empirical models are suitable for the prediction of the membrane fouling indices based on the CFD simulation. The interpolating polynomial expressed in Eq. (13) provided the optimal values for each one of the responses as well as the corresponding optimal operating conditions (Table 4).

The $F$-values of MLSS for all responses (except DO concentration) are the largest suggesting that the biomass concentration has the predominant effect over the air-flow rate and the bubble diameter (Fig. 4). Membrane shear stress increased with MLSS within the practical range though higher MLSS restrains the strain rate (Table 4). But high biomass concentration is truly detrimental for particle back transportation by increasing the total number of particles in Eq. (12) and by restraining the strain rate $\gamma_{w}$ and 
Table 3

ANOVA analysis of standard statistics for the second order empirical model.

\begin{tabular}{|c|c|c|c|c|c|c|}
\hline Response & $p$-Value & Model $F$-value & $R$-Squared & Adj $R$-Squared & Pred $R$-Squared & Adeq precision \\
\hline Shear stress & $<0.0001$ & 612.41 & 0.9984 & 0.9967 & 0.9958 & 78.99 \\
\hline PDP & $<0.0001$ & 818.35 & 0.9993 & 0.9981 & 0.9919 & 77.78 \\
\hline Strain rate & $<0.0001$ & 109.10 & 0.9879 & 0.9789 & 0.9562 & 36.72 \\
\hline DO & $<0.0001$ & 69.60 & 0.9500 & 0.9363 & 0.8918 & 25.51 \\
\hline
\end{tabular}

Table 4

Optimal operating conditions and response values for each one of the membrane fouling indices.

\begin{tabular}{|c|c|c|c|c|}
\hline \multicolumn{2}{|c|}{ Optimal targets } & Shear stress $(\mathrm{Pa})$ & $\operatorname{PDP}\left(\mathrm{m} \mathrm{s}^{-1} \mathrm{~J}^{-1}\right)$ & Strain rate $\left(\mathrm{s}^{-1}\right)$ \\
\hline \multicolumn{2}{|c|}{ Aeration intensity $\left(\mathrm{m}^{3} \mathrm{~h}^{-1}\right)$} & 2.00 & 2.00 & 2.00 \\
\hline \multicolumn{2}{|c|}{ Bubble diameter (mm) } & 4.83 & 4.88 & 4.88 \\
\hline \multicolumn{2}{|c|}{$\operatorname{MLSS}\left(\mathrm{mg} \mathrm{L}^{-1}\right)$} & 18,000 & 6000 & 6000 \\
\hline \multirow[t]{4}{*}{ Response } & Shear stress $(\mathrm{Pa})$ & 3.17 & 1.27 & 1.27 \\
\hline & $\operatorname{PDP}(\%)$ & $5.12 \mathrm{e}^{-2}$ & $1.06 \mathrm{e}^{-2}$ & $1.06 \mathrm{e}^{-2}$ \\
\hline & Strain rate $\left(\mathrm{s}^{-1}\right)$ & 115.65 & 174.97 & 174.97 \\
\hline & $\mathrm{DO}\left(\mathrm{mg} \mathrm{L}^{-1}\right)$ & 1.37 & 3.19 & 3.19 \\
\hline
\end{tabular}

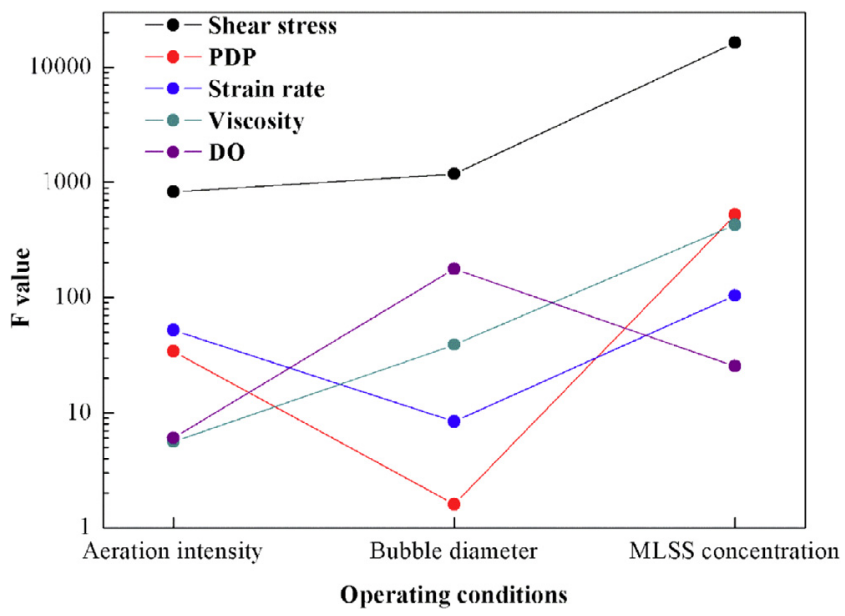

Fig. 4. The significance of operations of air intensity, bubble diameter and MLSS on responses of shear stress, PDP, strain rate, viscosity and DO.

decreasing $\frac{\phi_{w}}{\phi_{b}}$ both in Eq. (4) and in Eq. (7). As a result, PDP increased nearly fivefold when MLSS rise from $6000 \mathrm{mg} \mathrm{L}^{-1}$ to $18,000 \mathrm{mg} \mathrm{L}^{-1}$. Besides, a lower MLSS may be more energysaving due to lower demand for DO (Table 4). The optimal MLSS concentration was thus the lowest for PDP and strain rate but was highest for membrane shear stress (Table 4). The bubble diameter is unexpected to be more important than airflow rate on shear stress (Fig. 4). This is because the impact of bubble diameter on sludge viscosity is much more significant than airflow rate (Fig. 4). The optimal bubble diameter for PDP and strain rate is found to be the same as expected due to the positive correlation of strain rate and particle back transport velocity. The optimal bubble diameter for shear stress, however, is a little smaller. This can be explained by the slight interrelation between bubble diameter and MLSS on shear stress. While the high airflow rate is favored for the shear stress as expected, the high airflow rate is also preferred for PDP (Table 4). This is because the critical diameter of deposit particles is at about $3-12 \mu \mathrm{m}$ for the 15 studied tests, the particles tending to deposit is dominated by shear induced diffusion which is positive correlated to flow velocity according to Eq. (7).

A more intuitive observation can be obtained through plotting a 3-D plot with each one of the responses as a function of input factors. The membrane fouling related responses as a function of MLSS and bubble diameter under the medium airflow rate was presented (Fig. 5). The 3-D plot patterns for all the other studied airflow rates are quite similar concerning each one of the studied responses.

Fig. 5a shows that the shear stress increases obviously as a function of the MLSS. The shear stress is up to asymptotic values at the largest MLSS and at the bubble diameter ranging from 3 to $5 \mathrm{~mm}$. The plot shows a bunch of values where the shear stress is approximately constant. This confirms the slight interrelation between bubble diameter and MLSS, and suggests that a multiple optimization considering shear stress and other responses could be expected. With the DO restraining in $1.00 \mathrm{mg} \mathrm{L}^{-1}$ to $6.00 \mathrm{mg} \mathrm{L}^{-1}$, the maximum value of the shear stress at $3.17 \mathrm{~Pa}$ was obtained at airflow rate $=2.00 \mathrm{~m}^{3} \mathrm{~h}^{-1}$, MLSS $=18,000 \mathrm{mg} \mathrm{L}^{-1}$ and bubble diameter $=4.83 \mathrm{~mm}$ within the range of $1.00-10.00 \mathrm{~mm}$, at which the corresponding DO concentration was $1.37 \mathrm{mg} \mathrm{L}^{-1}$. The optimized bubble size is not consistent with (Böhm et al., 2013) who found that a bubble size larger than the channel depth was always preferred for wall shear stress measured with the electro-diffusion method (EDM). One probable explanation is that the viscosity of electrolyte they used for data recording is comparable to the one of water and $\mu=10^{-3} \mathrm{~Pa}$ s was used in the shear stress calculation. However, the optimized bubble size in this study is quite similar to the one of another publication of theirs (Drews et al., 2010). In that study, rheological properties of typical MBR mixed liquor were used (power-law-fluid, $\mathrm{k}=0.081, \mathrm{n}=0.42$ ) and the optimal bubble size was found to be 3 to $5 \mathrm{~mm}$ with a channel depth of 3 to $9 \mathrm{~mm}$. In fact, with the bubble size increasing, the air velocity increased in the riser zone and less gas entered into the down comer zone which together contribute a higher drag force to the liquid phase (Wesselingh and Bollen, 1999). But the higher bubble diameter is, the smaller the specific surface area is. With further increase of bubble diameter, the liquid velocity will experience a decrease due to the reduction of gas-liquid interface area.

The impact of MLSS on PDP is two sides concerning Eq. (12), namely the increase of percentage of particle deposition, $w_{\alpha}$, by reducing of shear-induced diffusion according to Eq. (7) and the increase of biomass concentration, $\phi_{b}$. So, the PDP is obviously increased with MLSS as expected (Fig. 5b). The bubble diameter smaller than $2 \mathrm{~mm}$ is found to be detrimental for particle detachment especially at a high MLSS concentration. The optimal bubble diameter is at around 4.5 to $5.0 \mathrm{~mm}$ for a high MLSS concentration for a minimum PDP. But in general, the PDP is less sensitive to bubble diameter especially at a low MLSS concentration (Fig. 5b). This demonstrates that the changing of bubble diameter contributes more for membrane shear stress and thus the cake layer peel-off 

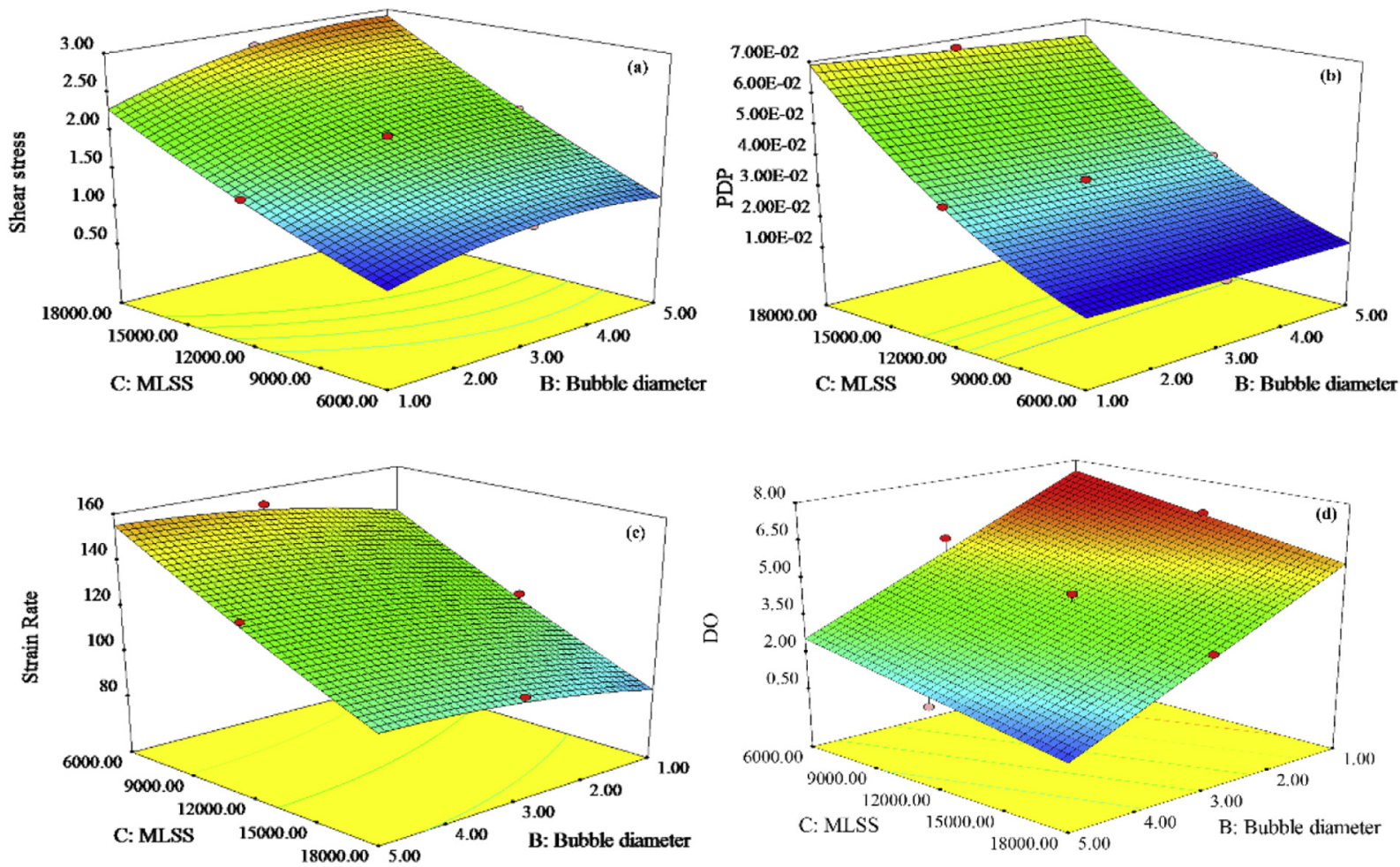

Fig. 5. Membrane scouring indices of shear stress (a), PDP (b), strain rate (c) and DO (d) as a function of bubble diameter and MLSS.

Table 5

Optimal operating conditions and response values considering the maximization of multiple responses.

\begin{tabular}{|c|c|c|c|c|}
\hline \multicolumn{2}{|c|}{$\begin{array}{l}\text { Propensity } \\
\text { Optimal targets }\end{array}$} & $\begin{array}{l}\text { Shear stress }=\text { PDP } \\
\text { Shear stress } \\
\text { PDP }\end{array}$ & $\begin{array}{l}\text { Shear stress }>\text { PDP } \\
\text { Shear stress } \\
\text { PDP }\end{array}$ & $\begin{array}{l}\text { PDP }>\text { Shear stress } \\
\text { Shear stress } \\
\text { PDP }\end{array}$ \\
\hline \multicolumn{2}{|c|}{$\begin{array}{l}\text { Aeration intensity }\left(\mathrm{m}^{3} \mathrm{~h}^{-}\right. \\
\text {Bubble diameter }(\mathrm{mm}) \\
\text { MLSS }\left(\mathrm{mg} \mathrm{L}^{-1}\right)\end{array}$} & $\begin{array}{l}2.00 \\
4.86 \\
15,259\end{array}$ & $\begin{array}{l}2.00 \\
4.84 \\
18,000\end{array}$ & $\begin{array}{l}2.00 \\
4.88 \\
8820\end{array}$ \\
\hline Response & $\begin{array}{l}\text { Shear stress }(\mathrm{Pa}) \\
\text { PDP }(\%) \\
\text { Strain rate }\left(\mathrm{s}^{-1}\right) \\
\text { DO }\left(\mathrm{mg} \mathrm{L}^{-1}\right)\end{array}$ & $\begin{array}{l}2.67 \\
3.67 \mathrm{e}^{-2} \\
130.08 \\
1.76 \\
0.51\end{array}$ & $\begin{array}{l}3.05 \\
5.11 \mathrm{e}^{-2} \\
115.71 \\
1.35 \\
0.54\end{array}$ & $\begin{array}{l}2.18 \\
1.49 \mathrm{e}^{-2} \\
161.69 \\
2.75 \\
0.66\end{array}$ \\
\hline
\end{tabular}

than for the particle deposition and membrane gel-like layer formation due to the small particle size (Wibisono et al., 2014). Besides, when considering the particle weighting factor according to the cake filtration mechanism (Kozeny-Carman relationship) (Jiang et al., 2007), the most abundant particles $(1.75 \mu \mathrm{m})$ can be carried away from the membrane only with a critical flux of $7.13 \mathrm{~L} \mathrm{~m}^{-2} \mathrm{~h}^{-1}$, which is quite low for a practical micro filtration process. These indicate that biomass concentration should be constrained and operation from biological consideration or flocculants addition should aim at reducing the small particle production and improve their degradation for a minimum PDP (Zhang et al., 2011, 2014).

The strain rate decreases with the increase of MLSS as expected (Fig. 5c). The impacts of airflow rate are as equal as MLSS for strain rate whereas bubble diameter hardly affects (Fig. 4). The MLSS concentration is expected to be high in MBR, therefore, it only can be compensated by a high airflow rate to generate a high strain rate for the purpose of particle back transport. It needs to point out that high biomass concentration in MBR will cause a decrease in sludge size due to the stronger particle-particle friction and collision
(Massé et al., 2006). And a high airflow rate may worsen the situation.

DO concentration is also presented in Fig. $5 d$ as a function of the MLSS and bubble diameter at an air flow rate $=1.50 \mathrm{~m}^{3} \mathrm{~h}^{-1}$. As expected, the DO concentration decreases with the MLSS and increases with bubble diameter. There is a certain proportion of areas where DO concentration is lower than $1.00 \mathrm{mg} \mathrm{L}^{-1}$, so the DO concentration needs to be constrained during the responses' optimization.

\subsection{Multiple responses optimization}

To alleviate reversible membrane fouling in MBR process, it needs to obtain a larger membrane shear stress for the removal of cake layer and a lower particle deposition propensity at the same time. However, according to the single response analysis, there are some conflicts for these two objectives. For example, the high MLSS is favorable for shear stress but detrimental for PDP. Therefore a multiple responses optimization was carried out to justify these two objectives for a maximum alleviation of rever- 

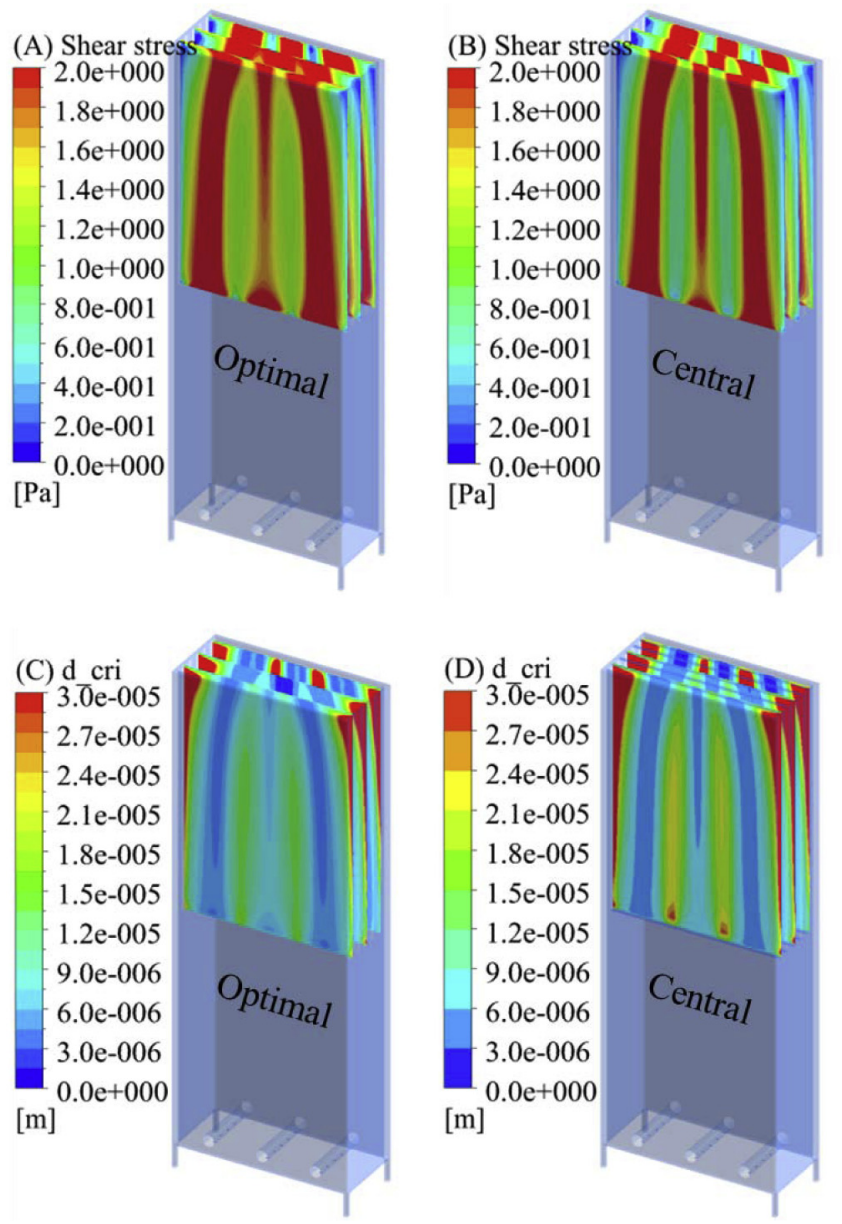

Fig. 6. Shear stress distribution on and critical particle diameter deposition on membrane surfaces with (A) and (C) for the run of optimized condition (airflow rate $=2.0 \mathrm{~m}^{3} \mathrm{~h}^{-1}$, MLSS $=8820 \mathrm{mg} \mathrm{L}^{-1}$, bubble size $\left.=4.88 \mathrm{~mm}\right)$ and with (B) and (D) for the run of center condition (airflow rate $=1.5 \mathrm{~m}^{3} \mathrm{~h}^{-1}$, MLSS $=12000.0 \mathrm{mg} \mathrm{L}^{-1}$, bubble size $=3.0 \mathrm{~mm}$ ).

sible membrane fouling. The optimized operating conditions for the maximization of shear stress and PDP of different propensities with the DO concentration constrain are presented (Table 5). As expected, highest air flow rate and moderate MLSS concentration are optimal for the case where shear stress and PDP are equally weighed. Highest MLSS and air flowrate are preferred when shear stress is biased and the optimal MLSS concentration drop to $8820 \mathrm{mg} \mathrm{L}^{-1}$ when PDP is preferred (Table 5). Comparing data from that of in Tables 3 and 4, it can be observed that the optimal bubble diameters fall in 4-5 mm. The reason may be two folds. The membrane shear stress is mainly contributed by liquid phase which is driven by the momentum transferred by gas phase. This momentum is a product of specific surface area of bubble, relative velocity between two phases and dynamic viscosity (Tritton, 1988). Larger bubbles have a higher relative velocity but a lower specific area and vice versa. Besides, with a high velocity, large bubbles generating a low liquid viscosity also leads to a low shear stress. As a result, a medium bubble size seems to be suitable in this study. Nevertheless, the shear stress of the case PDP > Shear stress is large enough due to the high MLSS concentrations adopted for the RSM study when compared to the literature reports (Liu et al., 2016; Taha and Cui, 2002). Comparing the optimized case to the center point run, it can be seen that the shear stress is higher and PDP is lower for the optimized operating conditions (Fig. 6).

\section{Conclusions}

A numerical approach combining a 3-D two-phase flow CFD model and Response Surface Methodology was used for reversible membrane fouling control. The significance order of factors are MLSS $>$ bubble diameter $>$ aeration intensity and MLSS > aeration intensity $>$ bubble diameter for shear stress and PDP, respectively. High MLSS is favorable for shear stress but also increases the PDP. With a propensity for PDP and a DO concentration constrain, the optimal operations for reversible membrane fouling control in a lab-scale MBR was airflow rate of $2.0 \mathrm{~m}^{3} \mathrm{~h}^{-1}$, MLSS of $8820 \mathrm{mg} \mathrm{L}^{-1}$ and bubble diameter of $4.88 \mathrm{~mm}$.

\section{Acknowledgements}

This work is funded by the Major Science and Technology Program for Water Pollution Control and Treatment of China (2015ZX07203-005) and the National Natural Science Foundation of China (No. 51278483).

\section{Appendix A. Supplementary data}

Supplementary data associated with this article can be found, in the online version, at http://dx.doi.org/10.1016/j.biortech.2016.12. 027.

\section{References}

Amini, E., Mehrnia, M.R., Mousavi, S.M., Mostoufi, N., 2013. Experimental study and computational fluid dynamics simulation of a full-scale membrane bioreactor for municipal wastewater treatment application. Ind. Eng. Chem. Res. 52, 9930 9939.

Anderson, M., Whitcomb, P., 2005. RSM Simplified: Optimizing Processes Using Response Surfaces Methods for Design of Experiments. Productivity Press, New York.

ANSYS, 2014. FLUENT User's Guide. PERA GLOBAL, The United States.

Belfort, G., Davis, R.H., Zydney, A.L., 1994. The behavior of suspensions and macromolecular solutions in crossflow microfiltration. J. Membr. Sci. 96, 1-58.

Böhm, L., Kraume, M., 2015. Fluid dynamics of bubble swarms rising in Newtonian and non-Newtonian liquids in flat sheet membrane systems. J. Membr. Sci. 475, 533-544.

Böhm, L., Drews, A., Kraume, M., 2013. Bubble induced shear stress in flat sheet membrane systems-serial examination of single bubble experiments with the electrodiffusion method. J. Membr. Sci. 437, 131-140.

Bowen, W.R., Sharif, A.O., 1998. Hydrodynamic and colloidal interactions effects on the rejection of a particle larger than a pore in microfiltration and ultrafiltration membranes. Chem. Eng. Sci. 53, 879-890.

Chen, J., Zhang, M., Li, F., Qian, L., Lin, H., Yang, L., Wu, X., Zhou, X., He, Y., Liao, B.Q. 2016. Membrane fouling in a membrane bioreactor: high filtration resistance of gel layer and its underlying mechanism. Water Res. 102, 82-89.

Cockx, A., Do-Quang, Z., Audic, J.M., Line, A., Roustan, M., 2001. Global and local mass transfer coefficients in waste water treatment process by computationa fluid dynamics. Chem. Eng. Process. 40, 187-194.

Davis, R.H., 1992. Modeling of fouling of crossflow microfiltration membranes. Sep. Purif. Methods 21, 75-126.

Davis, R.H., Sherwood, J.D., 1990. A similarity solution for steady-state crossflow microfiltration. Chem. Eng. Sci. 45, 3203-3209.

Drew, D.A., Schonberg, J.A., Belfort, G., 1991. Lateral inertial migration of a small sphere in fast laminar flow through a membrane duct. Chem. Eng. Sci. 46, 32193224.

Drews, A., Prieske, H., Meyer, E.L., Senger, G., Kraume, M., 2010. Advantageous and detrimental effects of air sparging in membrane filtration: bubble movement, exerted shear and particle classification. Desalination 250, 1083-1086.

Dumont, E., Fayolle, F., Sobolik, V., Legrand, J., 2002. Wall shear rate in the TaylorCouette-Poiseuille flow at low axial Reynolds number. Int. J. Heat Mass Transfer 45, 679-689.

Elimelech, M., Gregory, J., Jia, X., 2013. Particle Deposition And Aggregation: Measurement, Modelling and Simulation. Butterworth-Heinemann, UK.

Hao, L., Liss, S.N., Liao, B.Q., 2016. Influence of COD: N ratio on sludge properties and their role in membrane fouling of a submerged membrane bioreactor. Water Res. 89, 132-141.

Hocaoglu, S.M., Insel, G., Ubay Cokgor, E., Orhon, D., 2011. Effect of sludge age on simultaneous nitrification and denitrification in membrane bioreactor. Bioresour. Technol. 102, 6665-6672.

Hong, H., Zhang, M., He, Y., Chen, J., Lin, H., 2014. Fouling mechanisms of gel layer in a submerged membrane bioreactor. Bioresour. Technol. 166, 295-302. 
Jiang, T., Kennedy, M.D., Yoo, C., Nopens, I., van der Meer, W., Futselaar, H. Schippers, J.C., Vanrolleghem, P.A., 2007. Controlling submicron particle deposition in a side-stream membrane bioreactor: a theoretical hydrodynamic modelling approach incorporating energy consumption. J. Membr. Sci. 297, 141-151.

Judd, S., 2011. The MBR Book-Principles and Applications of Membrane Bioreactors for Water and Wastewater Treatment. Elsevier, UK.

Lin, H., Zhang, M., Wang, F., Meng, F., Liao, B.-Q., Hong, H., Chen, J., Gao, W., 2014. A critical review of extracellular polymeric substances (EPSs) in membrane bioreactors: characteristics, roles in membrane fouling and control strategies. J. Membr. Sci. 460, 110-125.

Liu, X., Wang, Y., Waite, T.D., Leslie, G., 2015. Numerical simulation of bubble induced shear in membrane bioreactors: effects of mixed liquor rheology and membrane configuration. Water Res. 75, 131-145.

Liu, X., Wang, Y., Waite, T.D., Leslie, G., 2016. Fluid structure interaction analysis of lateral fibre movement in submerged membrane reactors. J. Membr. Sci. 504 240-250.

Massé, A., Spérandio, M., Cabassud, C., 2006. Comparison of sludge characteristics and performance of a submerged membrane bioreactor and an activated sludge process at high solids retention time. Water Res. 40, 2405-2415.

Meng, F., Zhang, H., Yang, F., Zhang, S., Li, Y., Zhang, X., 2006. Identification of activated sludge properties affecting membrane fouling in submerged membrane bioreactors. Sep. Purif. Technol. 51, 95-103.

Meng, F., Shi, B., Yang, F., Zhang, H., 2007. Effect of hydraulic retention time on membrane fouling and biomass characteristics in submerged membrane bioreactors. Bioprocess Biosyst. Eng. 30, 359-367.

Moreau, A.A., Ratkovich, N., Nopens, I., van der Graaf, J.H.J.M., 2009. The (in) significance of apparent viscosity in full-scale municipal membrane bioreactors. J. Membr. Sci. 340, 249-256.

Pittoors, E., Guo, Y., Van Hulle, S.W.H., 2014. Oxygen transfer model development based on activated sludge and clean water in diffused aerated cylindrical tanks. Chem. Eng. J. 243, 51-59.

Ratkovich, N., Chan, C.C.V., Berube, P.R., Nopens, I., 2010. Investigation of the effect of viscosity on slug flow in airlift tubular membranes in search of a sludge surrogate. Water Sci. Technol. 61, 1801-1809.

Ratkovich, N., Horn, W., Helmus, F.P., Rosenberger, S., Naessens, W., Nopens, I. Bentzen, T.R., 2013. Activated sludge rheology: a critical review on data collection and modelling. Water Res. 47, 463-482.

Rosenberger, S., Kirsten, K., Kraume, M., 2002. Rheology of activated sludge in membrane bioreactors. Eng. Life Sci. 2, 269-275.

Rosenberger, S., Evenblij, H., Tepoele, S., Wintgens, T., Laabs, C., 2005. The importance of liquid phase analyses to understand fouling in membrane assisted activated sludge processes-six case studies of different European research groups. J. Membr. Sci. 263, 113-126.

Schwarz, A.O., Rittmann, B.E., Crawford, G.V., Klein, A.M., Daigger, G.T., 2006. Critical review on the effects of mixed liquor suspended solids on membrane bioreactor operation. Sep. Sci. Technol. 41, 1489-1511.
Shen, L.-g., Lei, Q., Chen, J.-R., Hong, H.-C., He, Y.-M., Lin, H.-J., 2015. Membrane fouling in a submerged membrane bioreactor: impacts of floc size. Chem. Eng. J. 269, 328-334

Silva, V., Rouboa, A., 2015. Combining a 2-D multiphase CFD model with a response surface methodology to optimize the gasification of portuguese biomasses. Energy Convers. Manage. 99, 28-40.

Stricot, M., Filali, A., Lesage, N., Sperandio, M., Cabassud, C., 2010. Side-stream membrane bioreactors: influence of stress generated by hydrodynamics on floc structure, supernatant quality and fouling propensity. Water Res. 44, 21132124.

Taha, T., Cui, Z.F., 2002. CFD modelling of gas-sparged ultrafiltration in tubular membranes. J. Membr. Sci. 210, 13-27.

Tchobanoglous, G., Burton, F.L., Stensel, H.D., 2002. Wastewater Engineering: Treatment and Reuse. McGraw Hill Higher Education, Wakefield.

Tijing, L.D., Woo, Y.C., Choi, J.-S., Lee, S., Kim, S.-H., Shon, H.K., 2015. Fouling and its control in membrane distillation-a review. J. Membr. Sci. 475, 215-244.

Tritton, D.J., 1988. Physical Fluid Dynamics. Oxford Science Publications.

Wagner, D.S., Ramin, E., Szabo, P., Dechesne, A., Plosz, B.G., 2015. Microthrix parvicella abundance associates with activated sludge settling velocity and rheology-quantifying and modelling filamentous bulking. Water Res. 78, 121132.

Wang, Z., Wu, Z., 2009. A review of membrane fouling in MBRs: characteristics and role of sludge cake formed on membrane surfaces. Sep. Sci. Technol. 44, 35713596.

Wang, Z., Ma, J., Tang, C.Y., Kimura, K., Wang, Q., Han, X., 2014. Membrane cleaning in membrane bioreactors: a review. J. Membr. Sci. 468, 276-307.

Wesselingh, J.A., Bollen, A.M., 1999. Single particles, bubbles and drops. Chem. Eng. Res. Des. 77, 89-96.

Wibisono, Y., Cornelissen, E.R., Kemperman, A.J.B., van der Meer, W.G.J., Nijmeijer, K., 2014. Two-phase flow in membrane processes: a technology with a future. J. Membr. Sci. 453, 566-602.

Wilén, B.-M., Jin, B., Lant, P., 2003. The influence of key chemical constituents in activated sludge on surface and flocculating properties. Water Res. 37, 21272139.

Yang, M., Wei, Y., Zheng, X., Wang, F., Yuan, X., Liu, J., Luo, N., Xu, R., Yu, D., Fan, Y., 2016. CFD simulation and optimization of membrane scouring and nitrogen removal for an airlift external circulation membrane bioreactor. Bioresour. Technol. 219, 566-575.

Yu, H., Lin, H., Zhang, M., Hong, H., He, Y., Wang, F., Zhao, L., 2014. Membrane fouling in a submerged membrane bioreactor with focus on surface properties and interactions of cake sludge and bulk sludge. Bioresour. Technol. 169, 213-219.

Zhang, H., Gao, J., Jiang, T., Gao, D., Zhang, S., Li, H., Yang, F., 2011. A novel approach to evaluate the permeability of cake layer during cross-flow filtration in the flocculants added membrane bioreactors. Bioresour. Technol. 102, 1112111131.

Zhang, Y., Zhang, M., Wang, F., Hong, H., Wang, A., Wang, J., Weng, X., Lin, H., 2014. Membrane fouling in a submerged membrane bioreactor: effect of $\mathrm{pH}$ and its implications. Bioresour. Technol. 152, 7-14. 